\title{
Contribuições da Psicologia às Lutas Transversais \\ Travadas em Meio às Metrópoles de Privilégios
}

\author{
Carolina dos Reis ${ }^{1}$ \\ Roberta Brasilino Barbosa ${ }^{2}$ \\ ${ }^{1}$ Universidade Federal do Rio Grande do Sul, RS. Brasil. \\ ${ }^{2}$ Universidade Federal do Rio de Janeiro, RJ, Brasil.
}

Resumo: Esse artigo tem por objetivo refletir sobre as possibilidades de contribuição da Psicologia a ações de enfrentamento a práticas violentas, e junto às lutas transversais travadas pelos grupos com os quais trabalhamos. Para tanto, partimos do conceito de lutas transversais de Michel Foucault, entendidas como lutas antiautoritárias e democratizantes que têm por alvo os mecanismos de dominação, exploração e submissão. Entendemos que os saberes psis, ao se colocarem a serviço das lutas transversais, podem servir como ferramentas de análise e enfrentamento a estes mecanismos. Nesse sentido, trazemos duas experiências de pesquisa e extensão realizadas em territórios que se encontravam em meio a processos de remoção, um deles na Comunidade Indiana, no bairro Tijuca, no Rio de Janeiro e o outro na Grande Cruzeiro, em Porto Alegre. Tais análises assumem o caráter de denúncia das violências decorrentes de gestões estatais, dando visibilidade às formas de submissão que operam pela produção do que chamaremos de uma "subjetividade culpada" e pela inscrição das populações alvo das remoções no lugar de não cidadãos, de sujeitos de um não direito. Buscaremos, ainda, evidenciar as articulações entre essas ferramentas de produção de subjetividade e as problemáticas materiais, decorrentes das desigualdades de acesso à moradia e à cidade. Por fim, afirmamos o caráter de resistência presente na compreensão de subjetividade como processo em constante construção e nas possibilidades de produzirmos rupturas nas práticas que encerram determinados modos de habitar e viver nas cidades como mais ou menos legítimos.

Palavras-chave: Direito à cidade, Remoções, Subjetividade, Lutas transversais, Psicologia. 


\title{
Contributions of Psychology to Cross-sectional Struggles Held at the Metropolis of Privileges
}

\begin{abstract}
This article aims to reflect on the possibilities of contribution of Psychology to actions to confront violent practices, and the transversal struggles waged by the groups with which we work. To do so, we start from the concept of transverse struggles of Michel Foucault, understood as anti-authoritarian and democratizing struggles that aim at the mechanisms of domination, exploitation and submission. We understand that psis knowledge, when placed in the service of the transversal struggles waged by the groups with which we work, can serve as tools of analysis and coping with these mechanisms. In this sense, in this article, we bring two research and extension experiments carried out in territories that were in the midst of removal processes, one in the Indiana Community, in the Tijuca neighborhood in Rio de Janeiro, and the other in the region of Grande Cruzeiro in Porto Alegre. Such analyses assume the character of denunciation of the violence arising from state management, promoted through the removal processes of Indiana and part of the Grande Cruzeiro, giving visibility to the forms of submission that operate through the production of what we will call a "guilty subjectivity" and by the inscription of the target populations of the removals in the place of non-citizens, of subjects of a non-right, of illegitimate inhabitants of the city. We will also seek, with our analyses, to highlight the articulations between these tools of production of subjectivity and the concrete material problems arising from the inequalities of access to housing and the city. Finally, we affirm the character of resistance present in the understanding of subjectivity as a process in constant construction and in the possibilities of producing ruptures in practices that contain certain ways of living in cities as more or less legitimate.
\end{abstract}

Keywords: Right to the city, Removals, Subjectivity, Cross-fights, Psychology.

\section{Contribuciones de la Psicología a las Luchas Transversales que se Libran en Medio a las Metropoles de Privilegios}

Resumen: Este artículo tiene como objetivo reflexionar sobre las posibilidades de la contribución de la Psicología para hacer frente a las prácticas violentas, y junto con las luchas transversales que libranlosgruposconlosque trabajamos. Con estefin, partimos delconcepto deluchas transversales de Michel Foucault, entendido como luchas antiautoritarias y democratizadoras que apuntan a los mecanismos de dominación, explotación y sumisión. Entendemos que el conocimiento psis, al ponerse al servicio de las luchas transversales, puede servir como herramienta para el análisis y para hacer frente a estos mecanismos. En este sentido, traemos dos experiencias de investigación y extensión llevadas a cabo en territorios que se encontraban en medio de procesos de remoción, una en la Comunidad de Indiana, en el barrio de Tijuca, en Río de Janeiro y la otra en Grande Cruzeiro, en Porto Alegre. Dichos análisis asumen el carácter de denunciar la violencia resultante de la gestión estatal, dando visibilidad a las formas de sumisión que operan produciendo lo que llamaremos una "subjetividad culpable" y por la inscripción de las poblaciones objetivo de los retiros en el lugar de los no ciudadanos, de sujetos de un no derecho. También buscaremos resaltar las articulaciones entre estas herramientas de producción de subjetividad y los problemas materiales que surgen de las desigualdades en el acceso a la vivienda y la ciudad. Finalmente, afirmamos el carácter de resistencia presente en la comprensión de la subjetividad como un proceso en constante construcción y en las posibilidades de producir rupturas en las prácticas que incluyen ciertas formas de vivir y vivir en ciudades como más o menos legítimas.

Palabras clave: Derecho a la ciudad, Remociones, Subjetividad, Luchas transversales, Psicología. 


\section{Introdução}

Esse artigo parte de duas experiências de pesquisa e extensão realizadas em territórios que se encontravam em meio a processos de remoção, um deles na Comunidade Indiana, no bairro Tijuca, no Rio de Janeiro e o outro na região da Grande Cruzeiro em Porto Alegre. O texto tem por objetivo refletir sobre as possibilidades de contribuição da Psicologia a ações de enfrentamento a práticas violentas, e junto às lutas transversais travadas pelos grupos com os quais trabalhamos.

Ao falarmos em "lutas transversais", referimo-nos à forma como Foucault (1995) denominou as lutas que, embora sejam locais e busquem enfrentar as violências promovidas por instâncias de poder imediatas, têm pautas antiautoritárias e democratizantes. Isto é, criticam os excessos de opressão política que a concentração de riqueza implica; tensionam os regimes de verdade e os monopólios sobre a produção do verdadeiro, que impedem os saberes de circularem livremente. São lutas que afirmam o direito de ser diferente e criticam o governo das individualidades, que questionam as lógicas individualistas que fragmentam o sujeito de sua relação com os outros e, desta forma, dificultam a construção de uma vida em comum. Elas têm por alvo não tanto uma instituição ou um grupo, mas sobretudo determinadas formas ou técnicas de poder. Tornam-se, assim, transversais a outros territórios, onde vê-se igualmente esses excessos no exercício do poder (Foucault, 1995).

Por meio das lutas transversais não se busca simplesmente o enfrentamento a um ponto central, foco dos excessos do poder, mas aos seus efeitos periféricos, aos suportes móveis, instáveis e localizados que fazem emergir e proliferar os mecanismos de governo (Foucault, 1988/2006). Desta forma, tratam-se menos de lutas antagônicas, pois não se restringem a dois pontos contrários em disputa, e muito mais de lutas agônicas, isto é, imersas em uma multiplicidade de correlações de forças, integradas também por resistências plurais, transitórias, ora distribuídas, ora articuladas ao levante de grupos ou de coletivos.

Para Foucault (Foucault, 1995) as lutas transversais podem ser de três tipos: contra as formas de dominação, seja ela étnica, social ou religiosa, contra as formas de exploração econômicas e contra as formas de submissão que tem por alvo os processos de subjetivação. Essas diferentes formas de lutas não se confundem umas com as outras, tampouco são exclu- dentes, elas podem ocorrer de formas mais ou menos articuladas. Os mecanismos de submissão, por exemplo, precisam ser compreendidos na relação com os mecanismos de dominação e exploração, mas não são somente o efeito final desses dois últimos, eles mantêm, sobretudo, relações complexas e circulares uns com os outros.

Os saberes psis ao se colocarem a serviço das lutas transversais travadas pelos grupos com os quais trabalhamos podem servir como ferramentas de análise e enfrentamento aos mecanismos de dominação, exploração e submissão. Nesse sentido, neste artigo, tais análises assumem o caráter de denúncia das violências decorrentes de gestões estatais, promovidas em meio aos processos de remoção da Indiana e de parte da Grande Cruzeiro, dando visibilidade às formas de submissão que operam pela produção do que chamaremos de uma "subjetividade culpada" e pela inscrição das populações-alvo das remoções no lugar de não cidadãos, de sujeitos de um não direito, de habitantes ilegítimos da cidade. Buscaremos, ainda, com nossas análises, evidenciar as articulações entre essas ferramentas de produção de subjetividade e as problemáticas materiais, concretas, decorrentes das desigualdades de acesso à moradia e à cidade.

Importante elucidar que, ao falarmos nas formas de submissão que operam na produção de subjetividades, tomamos a subjetividade não como uma estrutura interna ao sujeito, mas como a compreende Foucault (1988/2006), enquanto um campo lutas em constante tensionamento em meio ao qual os sujeitos são convocados a fazer a experiência de si. São processos produzidos a partir dos jogos de verdade que oferecem sustentação ao dizer verdadeiro, aos conhecimentos considerados legítimos que descrevem, diferenciam, organizam, classificam identidades e diferenças por meios das quais nos reconhecemos como sujeitos, bem como aprendemos a agir, sentir, pensar e habitar o mundo. Esses jogos de verdade, por sua vez, estão circunscritos às suas condições de emergência históricas, políticas e econômicas. Trata-se, portanto, de um contínuo processo de vir a ser, marcado pelas contingências do presente.

Nesse sentido, ao falarmos nos mecanismos de dominação, exploração e submissão, não significa dizer que esses são elementos externos que agem sobre uma subjetividade internalizada. Em primeiro lugar, porque não basta que hajam enunciados que afirmem um lugar de não cidadania aos moradores 
e moradoras da Indiana e da Grande Cruzeiro, por exemplo, é preciso que estas e estes vão ao encontro dessa marcação, que se reconheçam a partir das marcas que lhes são destinadas. Em segundo lugar, porque não há uma vida ou uma subjetividade anterior aos jogos de poder e saber sobre os quais estes se inscrevem, não há um estado de pureza anterior ou para além das formas de submissão. A experiência de si é organizada e produzida, em meio a esses jogos e é parte deles. Por isso que não se trata de um jogo de forças entre dois polos antagônicos. Diversas são as estratégias de submissão, seus objetivos e interesses. Igualmente diversas são as formas de resistências, as possibilidades de fuga, circulação e inapreensão dos sujeitos.

Assim, ao provocarmos um deslocamento do debate da subjetividade como interioridade para os processos de subjetivação, destacando seu caráter de transformação, e ao afirmarmos as possibilidades de contribuição da Psicologia na compreensão dos jogos que operam sobre os modos de ser sujeito, ligados às condições concretas de existência, buscamos operar a partir das possibilidades de desmontar os dispositivos normalizantes que capturam e encerram a multiplicidade dos modos de existência. Tomamos, portanto, os processos de subjetivação em seu caráter de resistência e como ferramenta de ação política em meio as lutas transversais.

Frente a isso, buscamos apresentar alguns dos embates que circunscrevem os processos de remoção ocorridos na Indiana e na Grande Cruzeiro. Ao fazermos isso, buscamos menos descrever as práticas de resistência e mais utilizá-las, como sugere Foucault (1995), como catalisadoras, de modo a dar visibilidade às relações de poder, localizar algumas de suas posições, seus pontos de aplicação e alguns dos métodos utilizados. Nesse sentido, evidenciamos a forma como a metrópole vai se constituir como espaço de produção e legitimação de privilégios. Buscamos mostrar, ainda, como a fragilização das condições de vida das populações atingidas por esse processo compõem um modo de gestão que joga com as legalidades, ora garantindo direitos, ora colocando-os em suspensão, mantendo os moradores e moradoras das favelas na incerteza de suas condições de vida. Por fim, afirmamos que democratizar a cidade significa não somente oferecer igual acesso aos recursos dela, mas trata-se igualmente de romper com formas de aniquilação subjetivas que impe- dem a participação no exercício político de produção dessa cidade.

\section{Produção de submissões e resistências}

A chegada junto aos territórios da Grande Cruzeiro alvos da remoção decorrente da ampliação da Avenida Tronco se deu através de um projeto de tese vinculado ao Núcleo de Estudos em Políticas e Tecnologias Contemporâneas de Subjetivação da Universidade Federal do Rio Grande do Sul e de nossa aproximação com coletivos de militância. Esses coletivos lutam pelo direito à cidade em Porto Alegre, desenvolvendo ações com os diferentes grupos que tem ameaçados seu direito à moradia, seus modos de vida, suas condições de acesso e circulação pela cidade, bem como a pautas ambientalistas. A aproximação ocorreu em um momento de aparente desgaste dos coletivos de militância e de algumas lideranças comunitárias, diante do fato de que a população de maneira geral vinha cedendo às pressões do poder público e deixando suas casas. As várias tentativas de engajamento dos moradores em um processo mais amplo de luta pela permanência no entorno da Avenida vinha gradativamente se enfraquecendo. É importante evidenciar que a prefeitura havia garantido à comunidade que nenhuma família seria removida a força. Assim, para permanecer não era necessário nenhum esforço, a simples inação seria suficiente. Tratava-se simplesmente de se manter onde estava. Logo, o poder público não havia somente conseguido fazer com que os moradores aceitassem sair, mas sobretudo que eles se engajassem ativamente nesse processo.

A ampliação da Avenida foi incluída nas obras de organização do país para a Copa do Mundo FIFA de Futebol de 2014, pois serviria para o desvio do trânsito de veículos nos dias dos jogos. Porto Alegre sediou o total de quatro partidas de futebol ao longo de todo o evento esportivo. A obra não ficou pronta em tempo e tem, hoje, previsão de finalização para final do ano de 2022. O projeto de duplicação implicou a remoção de 900 residências, atingindo quase 1.500 famílias. Desde o início das obras em 2010, a avenida ficou tomada de restos de casas que se espalhavam por todo trajeto. A demolição das casas expunham os vizinhos ao risco de desabamento e a condições de vida insalubres.

Para a saída das famílias das casas, foram oferecidas pela prefeitura três alternativas: (1) aluguel social e reassentamento, (2) bônus moradia para compra de 
uma nova residência em outro local e (3) avaliação do imóvel e indenização. Os novos assentamentos seriam construídos pelos recursos do Programa Minha Casa, Minha Vida. A proposta inicial da prefeitura era de que os empreendimentos ficassem em regiões distantes da cidade, pela suposta ausência de terrenos vagos próximos a Avenida. No entanto, por ação de moradores e moradoras, lideranças comunitárias e dos movimentos sociais envolvidos, foram identificados e, posteriormente, desapropriados e/ou adquiridos 14 terrenos no entorno da Avenida para a construção das novas moradias. Obras essas que até o começo de 2019 ainda não haviam sido iniciadas.

A escolha sobre a modalidade da remoção era feita quando do cadastramento das famílias, em 2009. Nessa ocasião, as famílias não eram detalhadamente informadas acerca dos motivos do cadastramento. Havia somente uma vaga notícia de que haveria o processo de remoção, pois a prefeitura receava que a notícia pudesse inflar o contingente populacional da área. O início do cadastramento levou a proliferação de boatos e de uma sensação generalizada de insegurança nos moradores, agravados pelas ameaças relacionadas "ao que iria acontecer com as famílias que não buscassem resolver logo seu processo de saída da comunidade" (sic).

Nesse momento, diferentes grupos de militância passaram a se organizar. Havia lideranças comunitárias, vinculadas às representações no Orçamento Participativo, que buscavam estabelecer diálogos com o poder público em nome das comunidades que representavam. Bem como, organizações reunidas no Comitê Popular da Copa, que articuladas a outras lideranças representativas dos moradores e moradoras, passaram a agir em nome da defesa do direito à cidade e à moradia, denunciando as violências do poder público nas mídias, convocando audiências públicas com membros do executivo, legislativo, judiciário e Ministério Público, chamando a população para realização de protestos nas ruas.

Um dos focos de ação desse grupo era a exigência de transparência nas informações fornecidas pelo poder público. Ainda assim, a desinformação e a insegurança foram importantes políticas de convencimento utilizadas pela prefeitura, além do fato de o processo de remoção ser feito por meio de negociações individuais entre as famílias e o Governo. Ao individualizar o processo, a prefeitura desarticulava as resistências coletivas, jogava moradores e mora- doras uns contra os outros (circulavam boatos de que alguns teriam recebido mais benefícios que $o$ devido). As lideranças comunitárias e demais pessoas de referência, que buscavam impulsionar ações de permanência no local, tinham seus processos de saída acelerados no escritório do Departamento Municipal de Habitação, acabando com os movimentos que estas gestavam.

Por fim, a principal ferramentas de convencimento do governo municipal se sustentou na afirmação de que o reassentamento significava uma "grande oportunidade" para as famílias e para toda a comunidade. Era um "benefício" que lhes estava sendo ofertado, posto que representava o acesso gratuito a uma moradia regular e, com ela, o acesso a uma condição de cidadania e a uma suposta melhoria na qualidade de vida. Essa afirmação vinha atrelada à fala de algumas lideranças comunitárias de que eles sempre souberam que ocupavam a área irregularmente e que, portanto, não seriam merecedores de nada. Sair seria seu dever e receber a nova moradia, quase que um presente, "um negócio da China”, como dizia uma dessas lideranças. Em meio às diversas violências decorrentes da saída compulsória do território onde construíram as condições de sobrevivência, onde contam com o apoio comunitário, onde se situa a escola dos filhos, os atendimentos de saúde, as oportunidades de trabalho, as fontes de renda informais etc., evidenciam-se nessas falas violências outras, denunciadas pela presença de um mecanismo de submissão que se alia a exposição dessas populações a condições de vida precarizadas e opera pela exploração de um lugar de sabida vulnerabilidade frente a um Estado que, historicamente, age não pela proteção, mas pela violação de seus direitos, que fortalece uma lógica de culpabilização e criminalização dos modos de morar e sobreviver dessas famílias.

Ao dialogar com moradores e moradoras acerca do não engajamento contínuo em ações de luta pela permanência era unânime a fala de que a localização da moradia no entorno da Avenida era excelente, mas para muitos havia o medo da violência, a vontade de se afastar do estigma criminalizante que circunscreve moradores e moradoras de favelas, a precariedade das condições estruturais de algumas casas ou da própria região do bairro em que estavam, mas o que aparecia com mais força nessas conversas eram dois elementos. O primeiro deles era a afirmação com mais ou menos força de um lugar de não direito sobre o 
solo, expressa por frases como: "mas o terreno não era nosso", "mas eu não entrei com o pedido de usucapião na justiça", "é que eu não tenho os papéis", "é que aqui é área invadida, é área verde", "aqui é área da prefeitura, é área de risco", "nós sempre soubemos que um dia teríamos que sair", "sempre tiveram boatos que iam nos tirar daqui para fazer a Avenida”. O segundo era o de que a remoção representava a possibilidade de ter uma casa própria escriturada. Esse elemento estava menos vinculado ao ganho referente ao bem financeirizável, e mais a saída da condição de irregularidade e a ascensão ao lugar de cidadão frente ao Estado e ao restante da cidade.

O direito de propriedade funda um lugar de sujeito. Deixa-os menos vulneráveis ao poder arbitrário do próprio Estado. O que havíamos falhado, enquanto movimento social, em perceber até ali é que a condição de sujeito de direito não passa somente pelo acesso à saúde, educação, emprego, renda, cultura, lazer, mas justamente por esse campo de lutas contra as formas de submissão. A possibilidade de engajamento contínuo em práticas de luta contra ações de gentrificação passava pela superação do processo de aniquilação subjetiva que inscrevia essa população no lugar de não cidadão, de habitantes ilegítimos da cidade, a um lugar de insegurança, sobretudo quando a condição de cidadania fica a mercê das políticas estatais.

Esse sentimento de insegurança frente à manutenção das condições de vida é efeito não da ausência completa de direitos, mas da presença de mecanismos de suspensão dos mesmos. A fragilidade dos direitos adquiridos nos fala não da inexistência de uma lei que os proteja, mas da consciência de existência de um exercício de poder pelo Estado que se faz, por vezes, arbitrário, quando dispõe soberanamente dos recursos que tem diante de si. É o próprio Estado que protege, que também violenta quando coloca em ação mecanismos de exceção, quando segmenta a população entre aqueles que merecem investimento e esses que podem ter suas vidas expostas à morte $\mathrm{e}$ à fragilidade. As desigualdades territoriais da cidade nos oferecem um mapa das zonas de existência de vidas qualificadas e daquelas expostas ao Racismo de Estado (Foucault, 1975-1976/2005). O Estado dispõe do poder de fazê-los passar de uma zona a outra da cidade.

A propriedade privada passa a se constituir como uma ferramenta de engajamento do desejo, mais forte do que as dificuldades decorrentes de habitar zonas distantes, não somente dos espaços estruturados da cidade, de maior oferta de trabalho, mas sobretudo de locais que, pelas articulações com os vizinhos, parentes do entorno, associações de bairro, escolas etc., oferecem os suportes necessários para as condições de vida dessa população. Ela representa a possibilidade de circular de uma zona não somente física e legal da cidade a outra, mas também política e subjetiva. Dessa forma, as lutas em torno da democratização do acesso ao direito à cidade aproximam-se das lutas em torno do direito à cidadania e ao movimento de redemocratização político e social do país, mas aproximam-se igualmente das lutas pelas formas de ser sujeito.

É considerando dessa mesma maneira - que as discussões sobre direito à cidade aproximam-se das lutas pelas formas de ser sujeito - que a experiência na Comunidade Indiana Tijuca vem se dando, desde a inserção de um grupo interdisciplinar de extensão universitária da Universidade Federal do Rio de Janeiro. O grupo, atualmente composto por integrantes provenientes dos cursos e programas de pós-graduação de Psicologia, Arquitetura e Urbanismo e Planejamento Urbano, realiza diferentes ações na favela com seus moradores e moradoras, tendo como objetivo central colaborar com a luta política e a participação social a partir de atividades de mobilização dentro e fora da Indiana, entendendo que os problemas que ali existem não se tratam de questões locais e pontuais, mas que são consequências de um modelo de produção de cidade.

Localizada na zona norte da cidade do Rio de Janeiro, no bairro da Tijuca, a Comunidade Indiana é uma favela plana e está próxima a importantes ruas de acesso aos bairros vizinhos. Esse fato confere destaque a ela, uma vez que as demais favelas dessa região estão todas situadas no alto de morros. Outra importante característica que marca esse território é ser atravessado pelo rio Maracanã, assim como grande parte do bairro da Tijuca e de outros no entorno.

Indiana, como é chamada pelas lideranças do território, vem enfrentando, desde 2010, um cenário de políticas remocionais (somente concretizadas de forma parcial, muito centradas no campo da ameaça) vinculadas ao discurso de risco ambiental. A gestão municipal do então prefeito Eduardo Paes (à época, integrante do Partido do Movimento Democrático Brasileiro - PMDB) e de seu sucessor, o 
prefeito Marcelo Crivella (filiado ao Partido Republicano Brasileiro - PRB), se vale de argumentos técnicos para intensificar a insegurança das moradoras e moradores da região em relação à permanência em seu território.

A equipe de Eduardo Paes (então PMDB) fez uso de laudos elaborados a partir de vistorias técnicas de caráter estritamente visual, que buscavam viabilizar não apenas a remoção de edificações que ocupavam a faixa marginal de proteção do rio Maracanã, mas também de toda a favela. Dentre esses laudos, aqueles emitidos pela defesa civil, traziam em seu cabeçalho os timbres dos Jogos Olímpicos de 2016 que foram sediados na cidade do Rio de Janeiro, produzindo entre alguns moradores e moradoras da Indiana a desconfiança de ser esse o real motivo para remoção da favela ${ }^{1}$ (Garritano, Martins, Rezende, Santos, \& Barbosa, 2018).

Mais recentemente, a gestão de Marcelo Crivella (PRB) vem recorrendo de decisões judiciais em processo iniciado pela Defensoria Pública do Estado do Rio de Janeiro (DPERJ), acionada pela Comissão de Moradores da Indiana, para barrar a remoção parcial da favela ocorrida em 2012. O processo movido pela defensoria representando as moradoras e moradores foi um importante instrumento para a paralisação das remoções naquele período, mas a ambiguidade técnica presente na sentença judicial, emitida anos depois, trouxe uma série de elementos que relativizaram a proibição de novas remoções (Garritano et al., 2018).

"Proibição das demolições que permaneceram no local, geminada ou não, sem que antes apresente estudo técnico prévio [...] retirada do entulho que permanecem [sic] no local [...] devendo o local retornar ao estado anterior às construções clandestinas" ${ }^{2}$. Ao não especificar a documentação técnica exigida e ao orientar a retomada do local ao estado anterior às construções, a sentença abre margem a uma retomada de ações de remoção de moradoras e moradores da Indiana a qualquer momento, possibilitando mais insegurança de moradia. Tal fato foi acirrado em 2018, por um parecer emitido pelo Ministério Público do Rio de Janeiro (MPRJ) acerca desse processo, em que é justificada a supressão do direito à moradia a partir da negação do direito ao saneamento.

"Pede a demanda coletiva que permaneçam residindo sem água, sem [no] esgoto, nas margens e na calha do Rio Maracanã, em casas improvisadas e insalubres [sem atender à legislação urbanística, ambiental e sanitária]”. O Ministério Público afirmou com esse parecer que as moradoras e moradores da Indiana que resistiram às investidas da gestão municipal de Eduardo Paes (então PMDB) em removê-los são autores da escolha por permanecerem residindo em locais insalubres, que negligenciam diversas legislações, e acerca disso fazem-se importantes algumas ponderações. $\mathrm{O}$ fato mencionado no documento do MPRJ não pode ser homogeneizado como única experiência dentro da favela, embora o parecer produza essa orientação. O documento demonstra um distanciamento de seus autores da realidade do território, o que não significa que não produza efeitos, tanto fora, quanto dentro da própria favela, para moradores e moradoras dali. E uma última consideração refere-se à ausência de responsabilização da gestão municipal na garantia de direitos básicos, como ao saneamento e à moradia.

A partir de todo exposto, observa-se no território da Indiana um processo intenso de produção de insegurança em relação à moradia e ao direito a ela, impulsionada tanto pelas práticas remocionais recentes, quanto pela ambiguidade da decisão judicial acerca da remoção da favela. Tal fato é agravado pelo parecer do Ministério Público, bastante limitado e limitante, acerca da experiência do viver neste território, cabendo ainda ressaltar que a produção da insegurança que se opera neste contexto tem fortes laços com a construção de uma subjetividade culpada. Aos moradores e moradoras da Indiana é comum o direcionamento (inclusive entre eles e elas mesmas) de falas acusatórias acerca das águas turvas e malcheiro-

\footnotetext{
${ }^{1}$ As Olimpíadas produziram uma grande especulação imobiliária no bairro da Tijuca, promovida não apenas pela proximidade com o complexo esportivo do Maracanã (palco de importantes modalidades esportivas), mas também em virtude da expansão do metrô, meio de transporte que assume caraterísticas muito peculiares no Rio de Janeiro. O Comitê Olímpico Internacional impôs a realização de obras de mobilidade urbana, no entanto os traçados das linhas de metrô na cidade sofrem diversas críticas por terem se tornado prioritariamente instrumentos de especulação imobiliária, desrespeitando a consideração de critérios básicos como o volume diário de passageiros a serem atendidos pelo serviço.

${ }^{2}$ Processo no 0402292-65.2012.8.19.0001. Disponível em: http://www4.tjrj.jus.br/consultaProcessoWebV2/ consultaMov.do?v=2\&numProcesso=2012.001.355176-7\&acessoIP=internet\&tipoUsuario=\#. Acesso: 18 .jul.18.
} 
sas do rio Maracanã. Recebem e constroem o estigma de poluidores, que a partir das ações dos poderes executivo e judiciário do Rio de Janeiro, passa a ser a justificativa para a não manutenção das pessoas naquele lugar (Ferreira, 2018).

No entanto, todo esse movimento de produção de insegurança em relação à moradia e ao próprio direito a ela não vem desacompanhados de reações contrárias. As lideranças do território, em especial aquelas integrantes da Comissão de Moradores, tem se articulado em ações no Conselho Popular ${ }^{3}$ para implementação na Indiana de uma experiência aplicada em Porto Rico, que foi responsável por desenvolver um modelo de ferramenta de segurança fundiária, o Termo Territorial Coletivo (TTC) 4 .

No ano de 2018, em virtude dos impactos que a movimentação judicial aqui já mencionada gerou no território, escolhemos acompanhar, juntamente com moradores e moradoras crianças e jovens, o curso do rio Maracanã, desde a sua nascente na Floresta da Tijuca, até o seu deságue, na Baía de Guanabara, passando pela Indiana. Realizamos diferentes atividades de exploração das margens do rio, utilizando-nos de brincadeiras como estratégias de promoção de observações críticas acerca das condições do rio Maracanã em diferentes pontos do bairro da Tijuca (anteriores e posteriores ao trecho que passa pela Indiana). Como são os cheiros e a tonalidade das águas nos diferentes pontos? Há casas próximas e/ou sobre o rio apenas na Indiana? Em que partes o rio "some" e em que áreas ele está visível? É possível observar vegetação e animais no entorno dele em toda sua extensão? Existem deságues de outras águas no rio Maracanã? Como são essas águas? De onde elas vêm? O rio transborda em quais pontos? Quais histórias são contadas por aqueles e aquelas que moram ou transitam pelos pontos do rio onde ele transborda? Existem obras públicas para evitar os transtornos? Elas ocorrem ou ocorreram em toda extensão do rio?
Ao final de cada semestre letivo, quando as atividades são interrompidas em virtude do calendário acadêmico, comumente realizamos eventos culturais $^{5}$ na Indiana, nos quais apresentamos aos demais moradores e moradoras o que foi feito ao longo dos meses de trabalho. Seguindo essa metodologia, em 2018, construímos uma exposição interativa em que foram apresentados os principais "achados" durante as atividades de exploração do rio. E assim foi possível compartilhar áudios de entrevistas feitas com moradoras e moradores da Indiana afetadas por seu transbordo e alguns atuantes em projetos de proteção ambiental do rio; fotos em que estão registradas manilhas jogando esgoto doméstico provenientes de condomínios do entorno, parte deles construídos sobre o rio Maracanã; e vídeos que mostram afluentes com águas limpas, mas privatizadas, uma vez que foram cercadas por muros que demarcam a propriedade em que funciona um colégio particular frequentado pela elite tijucana.

As atividades realizadas contribuíram na construção de outras narrativas acerca do território da Indiana e daqueles e daquelas que lá residem. Conforme relatado por Garritano et al. (2018), os discursos hegemônicos que criminalizam e culpabilizam os moradores e moradoras da Indiana não apenas pela poluição do rio Maracanã, mas também pela própria ocupação do local, tem sido desnaturalizados e assim aberta a possibilidade de produção de novos discursos, contra hegemônicos e emancipadores, aliançados com um modelo de cidade em que há maior justiça e participação social. A potência catalisadora do trabalho realizado ficou evidenciada em uma fala de uma das lideranças da Indiana quando, em reunião no Conselho Popular em que eram discutidas estratégias alternativas de garantia de segurança fundiária, afirma que as atividades auxiliam na mobilização do coletivo, que ocorre a partir das crianças e jovens moradores e moradoras do território, ressoando e aguçando um sentimento

\footnotetext{
${ }^{3}$ Conforme disponível em: https://www.facebook.com/pg/conselhopopularrj/about/?ref=page_internal, o Conselho Popular é fruto da articulação entre moradoras e moradores de favelas, vilas e comunidades do Rio de Janeiro para a luta pelo direito à moradia e à cidade.

${ }^{4} \mathrm{O}$ termo territorial coletivo é uma estratégia de garantir segurança fundiária que se opera a partir de princípios como adesão espontânea, propriedade coletiva da terra, casas de propriedade individual, controle comunitário, acessibilidade para a perpetuidade. Recuperado de http://rioonwatch.org.br/?p=36289

${ }^{5}$ Buscamos associar a cultura ao que é afirmado por Fontes (2018), para quem a luta cultural precisa estar articulada à luta política, reconhecendo a imbricação entre igualdade e diferença. Para o autor, o direito à periferia é uma forma de compreensão do direito à cidade, que se opera a partir da valorização do ser periférico e por esse motivo ele ressalta que direito à igualdade precisa ser garantido concomitantemente ao direito à diferença.
} 
de pertencimento à cidade que extrapola para seus pais e vizinhos.

No entanto, é indispensável ponderar que as atividades de mobilização realizadas, e, portanto, seus efeitos na luta política e participação social de moradores e moradoras da Indiana, apenas se somaram a iniciativas já existentes no território. O coletivo de crianças e jovens com o qual realizamos as atividades de trânsito pela cidade para exploração do rio Maracanã já vem participando de outras atividades, no campo da cultura, do lazer e da educação ambiental, articuladas a partir de uma integrante da Comissão de Moradores. Da mesma forma, nós também apenas nos somamos às ações locais em desenvolvimento que visam oferecer segurança fundiária para a favela a partir da aplicação de um modelo implementado em Porto Rico, que vem sendo debatido entre as lideranças comunitárias de favelas fluminenses no espaço do Conselho Popular. Para a aplicação dessa estratégia é indispensável a mobilização do coletivo, em muito prejudicada quando a moradia é solicitada como uma esmola (e celebrados os menores indícios de conquista, até mesmo os falaciosos) e não exigida e buscada enquanto um direito ${ }^{6}$.

\section{A cidade como campo de disputa: entre metrópoles de privilégios e lutas transversais}

A culpabilização, a insegurança das condições de vida e de moradia, a insalubridade, ou mesmo a criminalização de moradores e moradoras de favelas não se encerram nos processos de remoção. Isso se evidencia nas precárias condições estruturais das casas e dos próprios bairros, no receio vivido frente a constante exposição aos efeitos das atuais políticas de segurança pública, na falta de acesso a emprego e renda, na exposição a serviços públicos precarizados. Ainda que seja visível, na cidade, a desigualdade de acesso ao solo, à moradia, ou, mesmo, ao trabalho, e, embora estejam essas moradoras e moradores cercados por outros milhares que enfrentam dificuldades muito próximas das suas, a problemática da desigualdade territorial é vivida como consequência das falências ou êxitos individuais. A relação com a moradia é atravessada pela compreensão de propriedade privada e individualizada. Os governos, ao assumirem uma postura de não enfrentamento à desigualdade de acesso à moradia e ao conviverem com a existência e crescimento das favelas, reforçam a ideia de que se tratam de problemas pessoais ou locais, resultantes das condições de pobreza, ignorando o ponto de encontro entre essa problemática e o modo de gestão das cidades.

O agravante é que os efeitos da ilegalidade da posse vão para além da ausência de propriedade sobre a terra e servem de base para outros processos de exclusão. Santos (1993), ao analisar o exercício do direito nas favelas, afirma que a falta de legalidade sobre a posse estende-se para as demais relações sociais e serve de fundamento para a invasão de casas por agentes da segurança pública e outros serviços governamentais. Além disso, muitos moradores e moradoras não acessam o sistema de justiça, nem sequer para denunciar violências sofridas, para não chamar atenção sobre a situação irregular de moradia.

Tal como a culpabilização, a insegurança e o medo, a ausência ou a fragilidade de acesso a direitos tampouco é uma novidade inaugurada pelas remoções. Ela é parte dos mecanismos de gestão que vão servir como potentes ferramentas de construção de uma aceitabilidade do poder Estatal, de sua capacidade de fazer a população agir, sem necessidade de uso da força física. Trata-se na maioria das vezes não da ausência completa de direitos, mas da presença de mecanismos de suspensão dos mesmos. O Estado entra no jogo das legalidades, move, interpreta, ignora, modifica a lei de acordo com os jogos de interesse que atravessam sua lógica de gestão das cidades. Para isso, dispõe de um aparato institucional, financeiro, de corpos técnicos, em uma relação díspar de poder contra os cidadãos individualmente.

Nesse jogo de legalidades, é importante considerar uma diferenciação em relação à insegurança de moradia, insegurança em relação ao direito à moradia e supressão desse mesmo direito. Tratam-se de nuances muitas vezes invisibilizadas em prol do destaque

\footnotetext{
${ }^{6}$ No território da Indiana essa problemática se apresenta de forma relacionada às características geográficas da região. Indiana é composto por duas áreas bastante distintas no que tange a fragilidade de condições de infraestrutura das casas, especialmente em virtude de problemas ocasionados pela negação do direito ao saneamento básico. Moradores e moradoras da área mais afetada por diversas vezes são assediados pelas gestões municipais com promessas de realocação, sendo a mais recente para um edifício bem próximo a Indiana. Fica evidente que a precarização provocada pela negação do direito é um grande estimulador para que moradores e moradoras celebrem essas promessas falaciosas, gerando um racha interno na favela, o que já presenciamos em assembléias de moradores.
} 
aos casos restritos em que o direito à moradia é retirado. Todas essas formas de violação estão bastante presentes e geram muitos impactos na experiência de alguns brasileiros e brasileiras, em especial em virtude de uma perspectiva de compreensão do direito à moradia enquanto um direito individual e meritocrático, e não um direito coletivo.

No entanto, não se pode esquecer também que se experimenta no Brasil, um país com tamanha desigualdade social e racial (Georges, 2018), um fenômeno que é a construção de justificativa para retirada de um direito a partir da ausência de outro previamente retirado ou simplesmente não garantido. A produção da insegurança de moradia, da insegurança em relação ao direito à moradia e mesmo a supressão desse direito no território da Indiana, por exemplo, tiveram como fundamento a inexistência de cobertura de saneamento na região, um direito básico, previamente negado, que resulta desde ligações diretas do esgoto residencial no rio Maracanã, até perdas sazonais de pertences em virtude de alagamentos provocados pelas chuvas de verão na cidade. Já na Tronco, os efeitos da negação da segurança pública enquanto um direito a ser garantido a todas e todos (o que se evidenciava a partir da exposição à violência em torno do comércio varejista de psicoativos ilícitos, pelas disputas territoriais e pelas escolhas de enfrentamento da polícia, e a partir da estigmatização e criminalização dos moradores e moradoras decorrentes desse cenário) eram apontados como elementos que impulsionavam a aceitação da determinação de saída do seu local de moradia, ainda que em condições desfavoráveis. E dessa mesma forma outros direitos são igualmente negados. Somente no ano de 2018, especificamente durante os nove primeiros meses da intervenção militar federal no Rio de Janeiro, 177 estabelecimentos educacionais da Região Metropolitana tiveram ao menos um evento de disparos e trocas de tiros em um raio de 100 metros, o que foi responsável por ocasionar a suspensão de muitas aulas (Ramos, 2018). Crianças e jovens moradoras de favelas são restringidas no seu direito à educação, uma vez que o direito à segurança (de uns) impõe ações que acarretam tamanha violência nos territórios, a ponto de colocar em xeque o direito à vida? .
A partir dessa constatação deixamos um importante alerta: o que esse conjunto de distintos direitos negados têm em comum? A quem eles são negados! São moradores e moradoras de favelas, territórios específicos das cidades. Zonas em que é aplicado um estado de exceção, justificado a partir da necessidade de resolução de problemas em nome dos quais se suspendem direitos e garantias dos cidadãos e cidadãs. São pessoas cuja negação de direitos concretiza um tipo de poder com base no qual se torna possível a morte do outro enquanto elemento que constitui o poder do Estado (Mbembe, 2018).

Esse cenário concretiza também um determinado tipo de cidade, a cidade de privilégios. Nessa cidade, da qual não se pode esquecer sua marca primeira, a desigualdade, privilégio é aquilo que é garantido enquanto direito a quem tem direito. $\mathrm{Ou}$ seja, a noção de privilégio nas cidades não pode ser desmembrada de uma discussão sobre quem são os privilegiados, o que significa considerar para quem a lei (e portanto o direito que ela confere) é de fato um irredutível. E aqui irredutível precisa ser compreendido da maneira como afirmou Foucault (2008): uma opção além da qual não se pode ir, algo que não remete a nenhum raciocínio ou cálculo por ser um limitador na análise. Como apresentado por Ribeiro (2017), ser homem, cis, branco, heterossexual e europeu é apenas uma das formas possíveis de existência. E ainda que ela seja considerada aquela universal, ela é situada e parcial e essas diferenças precisam ser visibilizadas nesse debate sobre privilégios. Em especial em um país como o Brasil, constituído por uma estrutura colonial ainda vigente. Olhar para essa estrutura colonial se faz fundamental para que se possa identificar a associação entre privilégios e certos grupos sócio-raciais, especialmente no que tange os movimentos também desiguais de garantia de direitos, indispensáveis para que os mesmos possam permanecer sendo garantidos somente a uns e não a todos.

Outro elemento preponderante da cidade de privilégios é que antes de tudo ela é uma cidade privatizada, fruto de um processo de financeirização. E nessa cidade, o operador medo, que ganha terreno com a negação de direitos, exerce papel fundamen-

\footnotetext{
${ }^{7}$ No dia 20 de junho de 2018, Marcos Vinicius da Silva, de 14 anos, morreu depois de ser baleado durante um operação policial na Maré. O menino, que foi morto com um tiro na barriga disparado de um helicóptero da polícia, estava uniformizado e a caminho da escola (Ouchana, 2018).
} 
tal. Rolnik (2015) define privatização como despossessão do que é comum, do que é público. Nega-se o direito à saúde, tem-se planos de saúde privados; sucateia-se a escola pública, enquanto a rede de particulares expande-se cada vez mais; condomínios, carros particulares, seguranças privados. E até mesmo a gestão da cidade pode ser privatizada, servindo como exemplo bastante elucidativo o relatado por Faulhaber e Azevedo (2015) acerca da construtora Andrade Gutierrez, uma das maiores financiadoras das campanhas do ex-prefeito da cidade do Rio de Janeiro, Eduardo Paes (então PMDB) e também uma daquelas que esteve à frente de grande parte das obras de infraestrutura realizadas no período dos grandes eventos sediados pela cidade.

A lógica da cidade fica submetida à rentabilidade do capital, ocasionando o que Lefebvre (2001) denominou enquanto perda do valor de uso, da fruição, dos locais de encontro. O valor de troca e a generalização da mercadoria promovem aí destruições, na medida em que subordinam, cidade e realidade urbana, a partir da compra e venda de espaços, do consumo dos produtos, dos bens, dos lugares. E para tudo isso não se pode esquecer que o capitalismo precisa (e lança mão) do ilícito. Conforme aqui já relatado, a ilegalidade na ocupação de terrenos (em outras palavras, a busca pelo direito à moradia em cidades onde morar é um privilégio, parafraseando o Movimento dos Trabalhadores Sem Teto) é uma importante justificativa para não garantia de outros direitos básicos, e em alguns casos até mesmo para a não reclamação por eles

Por fim, o que queremos afirmar é que esses mecanismos de dominação e exploração que se aliam a distribuição desigual dos recursos na cidade de privilégios se constitui como importantes atravessamento na produção de subjetividades. O que é ser cidadão e cidadã numa cidade de privilégios? Quem de fato se identifica enquanto tal? Qual o papel das lutas transversais nesse processo, que é antes de tudo um processo de disputa? As experiências junto aos grupos de moradoras e moradores da Tronco e da Indiana tem nos mostrado que é sobretudo nesse campo, em que o que se coloca em disputa são os processos de produção de subjetividades, que a Psicologia pode oferecer-se como ferramenta para os grupos com os quais trabalhamos. Ferramenta de fortalecimento das práticas de enfrentamento às violências sociais.

\section{Últimas considerações}

Aproximar as discussões sobre direito à cidade das lutas pelas formas de ser sujeito parece significar uma atenção especial ao mecanismo de subjetivação denominado por Guattari e Rolnik (2005) como culpabilização. Para a autora e o autor são três os principais mecanismos pelos quais a lógica capitalística produz formas de ser e estar no mundo: infantilização (retirada de autonomia, da potência criativa no ser e estar), segregação (separação das formas de existência, nas quais cabe apenas se enquadrar) e culpabilização (produção de referências a partir das quais as subjetividades são comparadas e questionadas). Nos territórios com os quais temos nos aproximado, estão evidenciados processos de construção de subjetividades culpadas, seja por habitar em terreno "que não é seu", seja por lançar dejetos provenientes de sua moradia no rio que cruza a região habitada. No entanto, não se pode negligenciar a funcionalidade dessa forma de subjetivação à manutenção de privilégios na cidade, configurando-se, portanto, esse como um importante campo de inserção para a Psicologia junto às estratégias de resistência desenvolvidas nos territórios.

O rio Maracanã possui águas turvas e mal cheirosas em quase toda sua extensão, muito antes de alcançar a região ocupada pela Comunidade Indiana Tijuca, mas a experiência de culpa por esse fato não é dividida entre todas as moradoras e moradores da Grande Tijuca. Ao contrário, é somente o coletivo da Indiana que recebe e impõe entre seus pares a culpa pelo estado de poluição do rio. Muitas das moradoras e moradores da Tronco residem naquele local há cerca de 60 anos $^{8}$ e foram os responsáveis pela estruturação dos bairros, por meio de processos participativos de discussão e negociação com a prefeitura Municipal. Pela lei do Estatuto das Cidades são eles quem deveriam dispor do direito sobre a posse daquele solo. No entanto, a produção de culpabilidade impede que os privilégios sejam identificados enquanto tais ao construir submissão, em

${ }^{8}$ A Grande Cruzeiro, região que engloba a Avenida e as áreas de remoção, desenvolveu-se a partir da década de 1950, abrange 40 favelas com mais de 200.000 pessoas (Ávila et al., 2006). 
outras palavras, só se enxerga a existência de privilégios na ausência de culpa, porque um dos efeitos da culpa é a resignação.

Dessa forma entendemos que cabe à Psicologia dar visibilidade às formas de submissão que operam pela produção dessa "subjetividade culpada". Entendendo que é por esse movimento que as populações-alvo das remoções passam a ocupar o lugar de não cidadãos, de habitantes ilegítimos da cidade, destacamos as articulações entre essas ferramentas de produção de subjetividade e as problemá- ticas concretas que se desdobram das desigualdades de acesso à moradia e à cidade incentivadas pelas gestões estatais. A gestão das cidades hoje se institui hegemonicamente com base na lógica do privilégio pelo reforço de um caráter individual de subjetivação. Afinal, o próprio reconhecimento do sujeito enquanto sujeito de direito vem sendo definido pela lógica meritocrática individualista. E nesse aspecto a Psicologia tem importantes contribuições a oferecer, operando bifurcações, rupturas, abrindo espaço para múltiplas formas de ser sujeito.

\section{Referências}

Ávila, F., Araújo, J., Carracho, T. Azambuja, J., Brum, R., Costa, L. et.al. (2006). Memória dos bairros: Vilas da Grande Cruzeiro. Porto Alegre, RS: Unidade Editorial SMC.

Dreyfus, H. L., \& Rabinow, P. (1995). Michel Foucault, uma trajetória filosófica: Para além do estruturalismo e da hermenêutica. Rio de Janeiro, RJ: Forense Universitária.

Faulhaber, L., \& Azevedo, L. (2015). SMH: 2016 Remoções no Rio de Janeiro Olímpico. Rio de Janeiro, RJ: Mórula.

Ferreira, B. (2018). Da opacidade da técnica às práticas remocionais: Redesenhando instrumentos pela permanência da 'Comunidade Indiana' (Trabalho final de graduação). Faculdade de Arquitetura e Urbanismo, Universidade Federal do Rio de Janeiro, Rio de Janeiro, RJ, Brasil.

Fontes, L. (2018). Do direito à cidade ao direito à periferia: Transformações na luta pela cidadania nas margens da cidade. PLURAL, Revista do Programa de Pós-Graduação em Sociologia da USP, 25(2): 63-89.

Foucault, M. (1995). O sujeito e o poder. In H. L. Dreyfus \& P. Rabinow, Michel Foucault, uma trajetória filosófica: Para além do estruturalismo e da hermenêutica (pp. 231-251). Rio de Janerio, RJ: Forense.

Foucault, M. (2005). Em defesa da sociedade: Curso no Collège de France (M. E. Galvão, trad.). São Paulo, SP: Martins Fontes. (Originalmente publicado em 1975-1976)

Foucault, M. (2006). História da Sexualidade I: A vontade de saber (17a ed.; M. T. Albuquerque, \& J. A. G. Albuquerque, trad.). Rio de Janeiro, RJ: Graal. (Originalmente publicado em 1988).

Garritano, B., Martins, E., Rezende, J., Santos, L., \& Barbosa, R. (2018). Construindo juntos e juntas outras narrativas sobre o território: Contribuições no enfrentamento da desigualdade social. In A. Soligo, P. Bicalho, H. Maldonado, \& F. Portugal (Org.), Formação em Psicologia para transformação psicossocial na América Latina (pp. 301-312). Rio de Janeiro, RJ: Alfepsi.

Georges, R. (2018). País estagnado: Um retrato das desiguadades brasileiras (K. Mala, Coord.). Oxfam Brasil. Recuperado de https://www.oxfam.org.br/sites/default/files/arquivos/relatorio_desigualdade_2018_pais_estagnado_digital.pdf

Mbembe, A. (2018). Necropolítica: biopoder, soberania, estado de exceção, política da morte (R. Santini, trad.). São Paulo, SP: N-1 Edições.

Ouchana, G. (2018, 21 junho). Antes de morrer, jovem baleado na Maré disse para a mãe que tiros partiram de caveirão. O Globo. Recuperado de https://oglobo.globo.com/rio/antes-de-morrer-jovem-baleado-na-mare-disse-para-mae-que-tiros-partiram-de-caveirao-22807770

Ramos, S. (Coord.). (2018). Nove meses de intervenção federal: Muito tiro, pouca aula; pouca aula, + bandido: Infográfico. Rio de Janeiro: CESeC.

Ribeiro, D. (2017). O que é lugar de fala. Belo Horizonte, MG: Letramento: Justificando.

Rolnik, R. (2015). Guerra dos lugares: A colonização da terra e da moradia na terra das finanças. São Paulo, SP: Boi-Tempo.

Santos, M. (1993). A urbanização brasileira. São Paulo, SP: Hucitec. 


\section{Carolina dos Reis}

Professora do Programa de Pós-Graduação em Psicologia Social e Institucional da Universidade Federal do Rio Grande do Sul, Porto Alegre - RS. Brasil.

E-mail: carolinadosreis@gmail.com

(D) https://orcid.org/0000-0001-6482-2677

\section{Roberta Brasilino Barbosa}

Pesquisadora visitante em pós-doutorado no Programa de Pós-Graduação em Psicologia da Universidade Federal do Rio de Janeiro, Rio de Janeiro - RJ. Brasil.

E-mail: robertabrasilino@gmail.com

(iD) https://orcid.org/0000-0003-0943-916X

Endereço para envio de correspondência:

Rua Ramiro Barcellos, 2600, sala 401c, Instituto de Psicologia, Porto Alegre, RS, Brasil, CEP 90035-003

Recebido:24/06/2019

Aceito: 22/07/2019

Received:06/24/2019

Approved: 07/22/2019

Recibido: $24 / 06 / 2019$

Aceptado: 22/07/2019

Como citar: Reis, C., \& Barbosa, R. B. (2019). Contribuições da Psicologia às lutas transversais travadas em meio às metrópoles de privilégios. Psicologia: Ciência e Profissão, 39(n.spe 2), 87-99. https://doi.org/10.1590/1982-3703003225568

How to cite: Reis, C., \& Barbosa, R. B. (2019). Contributions of Psychology to cross-sectional struggles held at the metropolis of privileges. Psicologia: Ciência e Profissão, 39(n.spe 2), 87-99. https://doi.org/10.1590/1982-3703003225568

Cómo citar: Reis, C., \& Barbosa, R. B. (2019). Contribuciones de la Psicología a las luchas transversales que se libran en medio a las metropoles de privilegios. Psicologia: Ciência e Profissão, 39(n.spe 2), 87-99. https://doi.org/10.1590/1982-3703003225568 